IBIMA Publishing

Journal of Marketing Research and Case Studies

http://ibimapublishing.com/articles/JMRCS/2021/134710/

Vol. 2021 (2021), Article ID 134710, 9 pages, ISSN : 2165-7009

DOI : $10.5171 / 2021.134710$

Research Article

\title{
The Emerging Trend of Niche Tourism: Impact Analysis
}

\author{
Corina Larisa BUNGHEZ \\ Bucharest University of Economic Studies, Bucharest, Romania \\ E-mail: corinabunghez@yahoo.com
}

Received date: 7 September 2020 ; Accepted date: 25 January 2021; Published date: 24 May 2021

Academic Editor : Alexandra Cristina Dinu

Copyright (C) 2021. Corina Larisa BUNGHEZ. Distributed under Creative Commons Attribution 4.0 International CC-BY 4.0

\begin{abstract}
This research paper addresses the current tourism global market shift towards a niche tourism approach and focuses on some of the most significant tourism forms in this growing sector, analyzing both the current development and future evolution of these tourism trends, also taking into account the current global pandemic situation. The enormous versatility and potential of the selected niches are assessed, and the impact that these activities will have on mainstream tourism is highlighted, both economically and socially, as this trend continues to expand and integrate itself in the tourism global marketplace. The niche sectors analyzed in this research paper will fundamentally transform the tourism industry in the near future and, inevitably, alter the consumer experience by bringing more services and experiences into the mainstream tourism sector.
\end{abstract}

Keywords: Niche Tourism, Future Trends, Economic Impact

\section{Introduction}

Mass tourism is an important part of our daily lives; niche tourism is also growing at a rapid pace. Started as an expensive and elitist concept, targeting sophisticated travelers, who were enthusiastically interested in pursuing a diverse range of activities, niche tourism is now readily accessible to most people, being one of the fastest growing sectors within the domain of tourism.

The term niche tourism has been borrowed mostly from the term niche marketing, which has adopted the concept from a newer discipline, ecology. Hutchinson is considered to be the first who used the term niche, referring to a region in a vast area that is characterized by environmental factors which disturb the welfare of species (Hutchinson, 1957). In this sense, niche tourism can be linked to the particular natural and anthropogenic resources of a region, to the characteristic lifestyle of the tourists that engage in this type of activity and to their social status and their financial resources, etc. The niche tourism market, which is characterized by its name, targets a small number of consumers when compared to mass tourism, but, at the same time, it is a constant tourism market. Niche

Cite this Article as : Corina Larisa BUNGHEZ (2021)," The Emerging Trend of Niche Tourism: Impact Analysis", Journal of Marketing Research and Case Studies, Vol. 2021 (2021), Article ID 134710, DOI : $10.5171 / 2021.134710$ 
tourism is more identified with what tourists are doing than their number in a particular destination, at a particular time.

Any discussion of niche tourism needs to be considered against the other extreme of mass tourism. The rise of mass tourism, fueled by the growth in the aviation sector in the 1950s and 1960s, also gave rise to the backpacker tourist who later became the highly specialized and sophisticated middle-class traveler of the developed world (Lew, 2008).

Over time, the transition from mass tourism to niche tourism has been a slow and cumbersome process that necessitated a large amount of material and human resources in order to develop the much needed new and specialized infrastructure. The development of this infrastructure in the past decades has allowed people to reach destinations all over the world in record time. Keeping with the accelerated technological advancement, tourism will continue to expand its digitalization process. There are more and more applications for niche services nowadays, that are extremely personalized. These special applications perfectly know their target consumers and offer them suggestions based on their budget, their family structure and their traveling and browsing habits. On the other hand, for destination managers and traveling planners, who want to use tourism as a mechanism for economic growth, focusing on niche tourism offers greater opportunities because this attracts consumers that are willing to spend more money.

In order to position niche tourism products, Novelli considers the notion of an increasingly experienced group of tourists demanding specialist holidays to meet their specific desires (Novelli, 2005). The presence of activities, tourist attractions, settlements, food services and other facilities make up the fundamental components of niche tourism regarding mixed destinations, being aware of consumer needs and wants. The focal point of the niche tourism market is the focus on the demands and the expectations of the customers. The relation between supply and demand is well taken into consideration because tourists are in a never-ending search for a more satisfying experience during their holidays (C.T., 2010). In a world in which monotony is becoming more pronounced due to globalization, niche tourism is defined by its diversity and by new ways in which it can differentiate itself from the competition. Niche tourism doesn't have the negative implications that mass tourism has gotten along with its expansion, namely the negative impact on the environment and the degradation of socio-cultural relations.

If mass tourism is a standardized product aimed at a large segment of the market, niche tourism is situated at the opposite end of the tourism spectrum, being heterogeneous by nature and based on a larger demand for a more exclusive, unique and distinctive product.

The consumer is actively involved in the formation of a specific niche through its own consumerist practices. Because of this, in order to escape from the competition of mass tourism, the producer is no longer the sole identifier of adequate niche markets, because these niches are formed and developed by both producers and consumers, who act in a symbiotic mode in order to mutually benefit by it (Richards, 2011).

Over time, the different types of niche tourism have been presented in specialty literature in a random fashion. There are, however, some authors that have categorized them based on different criteria.

In order to better analyze the impact that certain types of niche tourism have over mass tourism, the classification made by Alex Papathanassis in his book, The Long Tail of Tourism, will be utilized (Paapathanassis, 2011). Tourism niches are built on persisting social trends such as:

- $\quad$ Sustainability (e.g. Eco-, Inclusive, Agro-tourism) 
- $\quad$ Experience-economy (e.g. Space-, Sport- \& Extreme-, Military-, Film, Dive-tourism)

- Self-development \& individuality (e.g. Cultural-, Educationaltourism)

- Hedonism \& voyeurism (e.g. Armchair-, Drug-, Sex-, Darktourism)

- Consumerism (e.g. Shoppingtourism)

- Conscious living (e.g. Health- \& Medical, Religious-, Wellnesstourism)

Consumer experience in tourism is defined as a conglomerate of personal reactions and emotions associated with tourism activities (Sugathan \& Ranjan, 2019). The creation of memorable experiences is necessary in order to attract new consumers and to keep the ones you already have loyal. All of the aforementioned tourism forms satisfy this requirement.

The impact of these forms of tourism is presented and analyzed in the following sections of the article, focusing on one form of tourism in each of the categories presented.

\section{Ecotourism}

Ecotourism is considered to be a niche segment that targets a small category of tourists, when compared to mass tourism. Nevertheless, ecotourism is the sector with the biggest growth in all the niche tourism markets.

The consequence of broadly defining the borders of what constitutes to be ecotourism is the cause behind the difficulty of properly measuring and assessing the market share and the size of this segment. Even so, estimates tell us that ecotourism makes up for roughly $20 \%$ of the tourism global market.

The eco tourist is the individual who visits the less developed areas with an appreciative, participatory and selfless attitude. This type of tourist interacts in a noninvasive way with local flora and fauna and uses natural resources in a conscious, reserved manner, while contributing through voluntary work or funds that are directed to the preservation of the area and the economic welfare of the local community (Ziffer, 1989).

Ecotourism has two specific components: specialized operations and non-specialized operations. The non-specialized ones include all common elements characteristic to all forms of tourism: tourist guides, adequate clothing, tourism agencies, hotels and transportation. The specialized ones are those which refer to the specific activities of ecotourism: eco cabins and hotels in urban or more secluded areas (resorts), protected areas, eco thematic attractions, services in other inaccessible areas by interesting means and local tour operators (natives).

There are independent groups successfully promoted as ecotourism products: aboriginal/indigenous tourism (related to cultural tourism), ornithology, celestial ecotourism (aurora borealis, astronomical observations, astrophotography), hiking and nature observation, landscapes photographing, outdoor education and research, etc. (Weaver, 2008).

Ecotourism attractions are primarily based on biodiversity and natural habitats that are, for the most part, unaffected by human activities. Thus, taking place in relatively isolated places, the current pandemic crisis will not impact this sector as severely as others. On the contrary, people will tend to visit more isolated places and ecotourism could benefit by this crisis. These zones require a specific conduct, in order to properly preserve and protect the tourism destinations so that they may keep their natural qualities and their sense of wilderness.

Ecotourism could indirectly compete with two tourist segments in terms of content and characteristics of the tourism product. These are cultural tourism and adventure tourism and they form, together with the ecotourism, what we call alternative tourism (Papathanassis, 2011). 
It is estimated that the future development of ecotourism in terms of application will depend on several factors, such as: revenue growth; increasing the education level; increased leisure time; population growth; easier, cheaper, faster and safer access to ecotourism destinations; greater care for the natural environment and people's feeling of alienation from it because of increasing urbanization and the development of technological elements.

Beyond all these elements, there is a necessity for properly trained people to educate the general tourists regarding the importance of nature conservation. Also, practicing ecotourism in these areas brings significant financial benefits that can be directed to further develop and maintain the natural parks and protected areas within the zone. Thus, ecotourism is a viable alternative for sustainable economic growth in these communities.

\section{Space Tourism}

Space tourism is an industry with extraordinary potential, but at present is limited by the conditions in which it can be done, because the prices are huge. Until the year 2019, the cost of a trip to the International Space Station aboard the Russian Soyuz spacecraft was 30 million dollars/flight. At present, the collaboration between NASA and SpaceX will inevitably lead to a commercial development. Axiom Space has already started the selling of tickets aboard the SpaceX capsule, at the price of 55 million dollars/ticket. The trip will last 10 days and will be directed to a privately funded orbital space station. Further technological advancement will massively lower the prices for space travel, starting with the amount of $\$ 200,000$ that Virgin Galactic assigned in the beginning. Space travel will become more accessible to a greater number of people, especially in relation to the results of a market analysis, which has found that potential consumers are very price sensitive (Goehlich, 2005). A study shows that at least 10 million people from around the world would be willing to spend a year's salary for space travel (Smith, 2001).
It is expected that the number of space travelers will grow somewhere to a million per year when the price of a ticket will be under $\$ 10,000$. According to research, rich and adventurous young people seem to form the most suitable target market due to their care-free rebellious character and the low comfort level that they are willing to accept in order to be among the first passengers in space (Crouch, et al., 2008). A study made by Futron Corporation in 2002 made the prediction that by 2021, the suborbital flight market will reach 15.000 passengers/annually, bringing in revenue of about 700 million dollars (Futron, 2002). We are in 2021 and this approximation is totally unattainable in the current global context. But it can be safely assumed that the number is not unachievable and we may see this happen in a few years. Another study made in 2006, in which 783 high income Australian respondents participated, showed that those who were mostly interested in space travel were thrill-seeking young men (Devinney, et al., 2006).

The economic potential of the development of space tourism is extraordinary. This type of tourism will bring massive economic and social benefits in the future, because it can be estimated that it will undoubtedly surpass aviation on Earth.

The progress of the space tourism sector would generate, alongside the indirect technological and scientific advancements, an important direct economic component that will lead to the exponential growth of this sector. Because space tourism has the potential of becoming its own branch in the tourism industry, the effects of this economic development will be significant, both for the companies and industries involved in the process, and for the evolution of our society as a whole. In this type of endeavor, the investor's primary concern is the return of the investment and the generation of profit. In order to do so, every process involved will be thoroughly made as efficient as possible. Space activities will therefore become a massive economic generator and the launch costs will dramatically plummet, which will lead 
to an acceleration in the further development of this industry.

Space tourism will become an activity that will include a very large number of people (both operators, and beneficiaries) and will generate important commercial profits in the next few decades. It is imperative that we recognize and realize the fact that, in the near future, space tourism may become as common as other forms of tourism. However, since the reality of space tourism is still quite far away, it may be safely assumed that the current Covid pandemic will not influence this branch of niche tourism. Because of the sensational experiences offered to the consumer, space tourism will become a major sector of the entire tourism industry, transforming this niche branch of tourism into one of the most important tourism activities of humanity.

\section{Cultural Tourism}

Cultural tourism is the most dynamic contemporary form of tourism, being interested in the lifestyle and traditions of particular communities or regions, built or natural heritage, artistic performances and products, cultural hubs and landscapes.

The first appearance of cultural tourism as a research topic has its origins at the beginnings of the $20^{\text {th }}$ century, but only in 2002 did the International Council on Monuments and Sites publish a formal definition regarding this form of tourism: cultural and cognitive-cultural tourism is the form of tourism that is focused on the cultural environment and that includes historical and cultural landmarks within a destination, and the values, arts, crafts, traditions, habits and lifestyle of the local populace.

Cultural tourism is defined by the World Tourism Organization (WTO 2012 Report) as "journeys whose primary or secondary purpose is the visiting of sites and the participation in events that represent a cultural and historical component which is part of a communities' cultural heritage". There are serious cultural and heritage/historical tourists who are motivated by the inherent characteristics of cultural sites and, at the other end of the spectrum, there are people who accidentally visit such venues but are not truly interested in the sites' inherent cultural and heritage assets (Morrison, 2013).

Cultural tourism includes, besides visiting historical sites, the opportunity to learn more about past human achievements. As a part of domestic tourism, these visits are a great source of admiration, national pride and learning about ancestors.

The complexity of cultural tourism is further generated by customer motivation diversity, induced by differences in education levels, tourism experience, quality of life and quality of the tourism products being offered (Davidson, 1993). Also, cultural tourism has been identified as one of the most rapidly growing areas of global tourism demand (Richards, 2005).

Cultural tourism is an important instrument for economic growth, generated by attracting visitors from outside the local host destinations. These visitors are partially or generally motivated by an interest in historical, artistic and scientific components, or by information regarding the lifestyle, the realities and the traditions of a particular community, region, group or institution. This kind of voyage focuses on the study of the cultural landscape, and this includes visual and theatrical arts, values, traditions, events and lifestyle. Cultural tourism is especially interesting for suppliers because, as a rule of thumb, people that focus strongly on cultural attractions spend more money than regular tourists. Also, they show a tendency toward staying longer at the destinations, which, in turn, brings even more revenue (Richards, 2007).

Because cultural tourism isprimarily focused on the visiting of cultural venues or museums and experiencing artistic products and performances, the current global pandemic has affected, to some extent, this important tourism sector. But people will always be interested in the lifestyles and traditions of different 
cultures, and as soon as the Covid pandemic loses momentum, we will definitely see a resurgence in cultural tourism demand.

\section{Armchair Tourism}

The one thing that history has taught us is that people are most innovative in difficult times. This also applies to the travel industry, where professionals and brands are doing their best to keep the interest in traveling at a high level, despite the current global Covid pandemic situation. This has resulted in the surprisingly successful overnight growth of armchair tourism. This adaptation happened because tourism is going through one of its darkest periods in a long time, and tourism specialists find themselves in the impossibility to change this situation. Indeed, this isn't the greatest of times for classic travels, but, in the meantime, we can opt for virtual travel. If, until more recently, the trend of virtual tourism was relatively ignored, because people preferred real experiences, more and more people are now glad that the technology that enables this type of tourism has advanced so much that it can now facilitate easy and comfortable access for many willing tourists.

Because lately, due to the current global pandemic, tourism has been mostly relegated to rescheduling holiday plans or postponing them, the phenomena of armchair tourism is currently growing at a rapid pace, enabling us to travel all over the world, virtually.

If tourism is not seen as a physical change of the hereabouts but rather as a change of ones' psychological state of recreation, education, adventure, or other purposes associated with tourism, armchair-tourism can also be included (Mazanec, et al., 2002).

Armchair-tourism has three main parts: books, television and the internet. Until the emergence of the internet, books were the armchair-tourism media because they were the best information source for life there. Nevertheless, new media has slowly overtaken the time spent on reading. Armchair-tourism such as travel magazines or cultural documentations are more focused on consumers aged 40 and older. Nevertheless, the younger generation should not be neglected since new developments will enhance the experience of watching $\mathrm{TV}$, increasingly attracting younger viewers (Papathanassis, 2011).

Many tourist boards are nowadays using more and more virtual content in order to attract customers and to encourage future visits. These can come in the form of digital events, which provide enriching cultural content and livestreaming video talks using live content from experts, partners and notable individuals. Tourist boards will also use dedicated web pages on which they will promote virtual experiences. Museums, safaris, or other interesting venues can therefore be experienced while enjoying the comfort of your own home.

There are destinations and travel brands which can keep the magic and inspiration of traveling alive even if it is virtually, from the armchair. Many travel brands and destinations are working on the premise that if the travel consumer can't come to us, we will go to the travel consumer. There are digital platforms where a plethora of extraordinary destinations can be accessed and visited by virtual means. Over 2500 museums all over the world are providing virtual tours for those who are interested. During these tours, tourists can enjoy rooms, shows and events, in which they can participate virtually.

Also, the exponential evolution of technology has another benefit. Even if virtual reality is, at present, only capable of recreating, to a limited degree, the destination that is being visited, we now have another tool at our disposal: augmented reality. This changes the way in which a visitor can explore a destination in real time. Augmented reality is the technology that gives the visitor information that can be superimposed over the real time landscapes or streets, using a digital device. This technology is being used in order to animate history and to bring back life into exhibits found in the most important museums and venues of the world. Having all these means at our 
disposal, we can therefore travel anywhere, anytime and we are no longer dependent on the caprices of weather or the uncertainty found in difficult times, such as the one we are experiencing nowadays.

\section{Shopping Tourism}

As studies have shown, shopping is one of the most sought out activities no matter where tourists go (Timothy, 2003). This activity gained traction with the development of theme parks, of malls and designer shops. Visiting a theme park or going shopping in another country and even inside the borders of your own country has become, for many tourists, a purpose in itself. Bill Bryson, an American travel and humor book author said that in the past, people used to build civilizations, but now they build shopping malls. Another American author, Erma Bombeck, affirms that the chances of entering into a store to buy a loaf of bread and exiting with just a loaf of bread are three billion to one. These aspects emphasize the worldwide consensus that, in our society, humans are unable to function without constantly going shopping.

When trying to define this special tourism sector, only one facet can be defined clearly, namely that this kind of tourism includes the purchase of goods, the most typical being clothes, shoes, leather goods and luxury foodstuff (Friedrich, 2006).

The main advantage a tour operator could enjoy is the fact that shopping tourism has a positive economic impact on the destinations and limited negative environmental and socio-cultural effects. Meaning local life, natural environment and cultural sites are not going to be disturbed nor destroyed since many traditional malls, factory outlets, and markets do already exist. To be more precise, economically, this implies: more secure jobs, as the malls will have a continuous number of visitors; tax income will increase due to the valueadded tax (VAT) of more sales; shopping tourism does not seem as seasonal as other tourism products; in addition, foreign tourists will increase the balance of payments (Papathanassis, 2011). Also, the environmental impact is almost nonexistent, this not being the usual norm with tourism activities. This happens because, neither accidentally nor by design, wildlife killing or vegetation being destroyed by tourists do not occur. There is also a sociocultural impact: a shopping mall is visited by locals as well as national or international tourists, and as such, it is seen as a positive attraction since access is not limited to neither of the two groups (Swarbrooke, 2002).

The Covid situation has temporarily shifted this type of tourism to a more domestic focused approach. People are now more inclined to go shopping in local tourism destinations. But shopping has become a life-dictating activity for many people, and even in the current difficult pandemic context, everybody goes shopping and we have become dependent on it.

\section{Wellness Tourism}

In our fast-paced society, we tend to often forget about ourselves. Because of this, health issues can arise due to stress, exhaustion and living a sedentary life. All these problems can be fixed by escaping into wellness centers. For more and more people, wellness is no longer a trend or a necessity, but has become a lifestyle.

The wellness industry has grown substantially in the last years, at a global level. The numbers are continually growing and the market value of the wellness industry has reached 580 billion Euros. Lots of hotels, airports and corporations have understood the importance of wellness, and thus provide some kind of wellness services to both guests and staff.

The wellness world is a global economy made out of multiple components: beauty and care, fitness, nutrition and alternative medicine. A popular perception regarding the importance of healthy diets, fitness and other health practices has been developed into whole new business sectors. As the healthy lifestyle movement gains more and more traction, auxiliary markets, ranging from food and beverage to hospitality, start offering more products that reflect the 
values of the health-conscious consumers. This is another example of the multiplier effect of tourism. Additionally, the Covid situation is the perfect incentive for healthier lifestyle choices. Thus, people are becoming more aware of the importance of overall health management and are more readily willing to pay for these kinds of services.

Wellness tourism is defined in the specialty literature as traveling associated with the practice of maintaining or improving personal states of being.

From 2015 until 2017, the wellness tourism market has grown annually by a margin of 6,5 \%. Until 2022, GWI anticipates that this market value will reach 919 billion dollars - representing $18 \%$ of global tourism - with over a billion wellness-oriented travels all over the globe (GWI, 2018).

Today, wellness tourism is much more than just the destination or the activities - it is an extension of the traveler's lifestyle and values. The wellness tourism sector is a large spectrum one, and offers are divided between many categories: fitness, healthy nutrition, therapeutic treatments (massages, beauty procedures). But every one of them is centered around enhancing the tourist state of being and state of mind.

Further opportunities are given to current trends, such as the alternative forms of medical therapies from Asia. However, these trends have to be recognized early enough and then must be implemented through serious, high-quality products. Beside the competitive criteria, such as price, or the kind and quality of services provided, the importance of the attractiveness of the surrounding area as a choice criterion should not be underestimated (Papathanassis, 2011).

Specialists estimate that, if the consumers' appetite for wellness services maintains its rate of growth, the wellness global tourism industry will reach one trillion dollars in the shortest of time.

\section{Conclusions}

There is enormous potential with all of the emerging niche tourism products presented in this paper. All of them arguably represent what one may designate as a megatrend, either at present or in the near future. Additionally, each of the selected products has incredible versatility because they don't target a particular "special" group of consumers, but instead, they appeal to a larger proportion of the population. In other words, the niches examined are not mutually exclusive in terms of their target market. The phenomena of tourism globalization by developing infrastructure and thus new destinations, and the technological advances in human transportation, with the usage of the megaship or the implementation of large-scale commercial space travel, will transform these megatrends into tourism behemoths, and will result in the creation of new specialized holiday niches that will generate huge profits and further expansion. The examples presented show a promising outlook for each of the niches examined, as the current global pandemic cannot but temporarily slow the inevitable growth of these tourism sectors.

There are three main aspects of the tourism industry that can be synthesized from this paper. Firstly, the tourism sector is in a constant, ever-growing direction, with more and more people willing to spend money in tourism activities. Secondly, the mainstream holiday package isn't as stable as it used to be, and it can be said that the current crisis in the world is a major influencing factor. Thirdly, there are some tourism niches that have great appeal and show incredible potential for the near future.

However, there are three more tour operating aspects that have to be taken into consideration when making assertions: the capacity risk, the consumers' perceived risk and the unknown reaction of the large tourism groups.

Higher profits can be generated when entering and developing niche markets. Because of this, there are many 
mainstream companies that have already entered into a number of niche markets. The technological advancement can thus be utilized by specialists in order to benefit, in a sustainable way, from each particular niche selected. Moreover, tourists are more pleased because the holiday experiences are tailored to their needs and wants, making the product more individualized and consumer-oriented. For the tourism industry as a whole, the growing of niche markets can be seen as a "holiday" from the usual negative practices regularly associated with mainstream tourism, such as environmental irresponsibility and questionable ethics. This means that when niche tourism fully matures and inevitably integrates itself into mass tourism, becoming mainstream, it will carry its benefits into the new tourism industry.

\section{References}

- C.T., G., 2010. Niche market study. Cape Town: s.n.

- Crouch, G. I., Devinney, T. M., Louviere, J. J. \& Islam, T., 2008. Modelling consumer choice behaviour in space tourism. Tourism Management, 30(3), pp. 441-454.

- Davidson, R., $1993 . \quad$ Tourism. London: Longman.

- Devinney, T., Crouch, G. I. \& Louviere, J., 2006. Going Where No Tourist Has Gone Before: The Future Demand for Space Tourism, s.l.: Future Choice Initiative.

- Friedrich, W., 2006. Shopping tourism impulses for growth of tourism and retail in Germany. s.l.:s.n.

- Futron, 2002. Space Tourism Market Study - Orbital Space Travel \& Destinations with Suborbital Space Travel, Wisconsin: Futron Corporation.

- Goehlich, R. A., 2005. A ticket pricing strategy for an oligopolistic space tourism market. Space Policy, Volume 21, pp. 293-306.

- GWI, 2018. Global Wellness Economy, s.l.: Global Wellness Institute.
- Hutchinson, G., 1957. Concluding Remarks. Cold Spring Harbor Symposia on Quantitative Biology, Volume 22, pp. 415-427.

- Lew, A. A., 2008. Long tail tourism: New geographies for marketing niche tourism products. Journal of Travel and Tourism Marketing, 25(34), pp. 409-419.

- Mazanec, J., Crouch, G., Brent Ritchie, J. \& Woodside, A., 2002. Consumer psychology of Tourism, Hospitality and Leisure. International Journal of Contemporary Hospitality Management, 14(2).

- Morrison, A. M., 2013. Marketing and managing tourism destinations. New York: Routledge.

- Novelli, M., 2005. Niche Tourism: Contemporary issues, trends and cases. Oxford: ButterworthHeinemann.

- Paapathanassis, A., 2011. The long tail of tourism. 1st ed. s.l.:Gabler.

- Richards, G., 2005. Cultural tourism in Europe, Wallingford: CABI.

- Richards, G., 2007. Cultural Tourism: Global and local perspectives. In: Binghampton: The Haworth Press Inc..

- Richards, G., 2011. Rethinking niche tourism in the network society. ATLAS.

- Smith, V., 2001. Space tourism. Annals of Tourism Research, Volume 28, pp. 238-240.

- $\quad$ Sugathan, P. \& Ranjan, K. R., 2019. Co-creating the tourism experience. Journal of Business Research, Issue 100, pp. 207-2017.

- Swarbrooke, J., 2002. The development and management of visitor attractions. Oxford: Elsevier Butterworth-Heinemann.

- Timothy, D., 2003. Shopping tourism, retailing, and leisure. s.l.:Channel view publications.

- Weaver, D., 2008. Ecotourism. Australia: Wiley\&Sons.

- Ziffer, K., 1989. Ecotourism: The Uneasy Alliance. Washington D.C.: Conservation International. 